\title{
A pH-responsive drug delivery matrix from an interpolyelectrolyte complex: preparation and pharmacotechnical properties
}

\author{
Jorge Andrés Montaña ${ }^{1}$, León Darío Perez ${ }^{2 *}$, Yolima Baena ${ }^{1 *}$ \\ ${ }^{1}$ Universidad Nacional de Colombia, Sede Bogotá, Facultad de Ciencias, Departamento de Farmacia, Grupo de \\ investigación Sistemas para la Liberación Controlada con Moléculas Biológicamente Activas, Bogotá D.C., Colombia, \\ ${ }^{2}$ Universidad Nacional de Colombia, Sede Bogotá, Facultad de Ciencias, Departamento de Química, Grupo de investigación \\ Macromoléculas, Bogotá D.C., Colombia
}

\begin{abstract}
Interpolyelectrolyte complexes, which constitute a type of polymeric material obtained through the selfassembly of oppositely charged polymers, exhibit interesting properties for use in the design of smart matrices for drug delivery. In the present study, a stoichiometric interpolyelectrolyte complex (SIPEC) composed of Eudragit E $\AA$ and Eudragit $\AA$ L100 was obtained at pH 6.0 and characterized and evaluated as a hydrophilic matrix for dexibuprofen. The formation of a SIPEC was monitored by $\zeta$-potential measurements and characterized using infrared spectroscopy, thermal analysis, and scanning electron microscopy. The results indicated that a SIPEC obtained under these conditions can be used as a matrix for controlling the release of dexibuprofen and exhibit a $\mathrm{pH}$-triggered release.
\end{abstract}

Keywords: Interpolyelectrolyte complex. Pharmacotechnical properties. Dexibuprofen. Controlled release. Hydrophillic matrix.

\section{INTRODUCTION}

Interpolyelectrolyte complexes (IPECs) are selfassembled materials formed in aqueous medium by two oppositely charged polyelectrolytes. IPECs exhibit interesting properties for use in pharmaceutical applications as polymeric drug carriers with controlled release, micro- and nanoencapsulation of biologically active substances, preparation of biodegradable and biocompatible membranes, and the design of systems for the delivery of proteins and genes (Devi, Maji, 2009; Bawa et al., 2011; Arora et al., 2011; Ramasamy et al., 2014; Čalija et al., 2013; Pergushov et al., 2013). Although these macromolecular complexes are mainly stabilized by electrostatic interactions between oppositely charged ionic groups on polymers, interactions such as hydrogen bonding, Van der Waals, and hydrophobic forces also contribute to their formation (Lankalapalli, Kolapalli, 2009).

\footnotetext{
*Correspondence: L. D. Perez. Universidad Nacional de Colombia, Sede Bogotá, Facultad de Ciencias, Departamento de Química, Grupo de investigación Macromoléculas, Carrera 30 \# 45-03, Bogotá D.C., (111311), Colombia. E-mail: 1dperezp@unal.edu.co

Y. Baena. Universidad Nacional de Colombia, Sede Bogotá, Facultad de Ciencias, Departamento de Farmacia
}

IPECs are obtained by blending aqueous solutions of the corresponding polyelectrolytes. Their formation is favored by entropy gain afforded by the release of lowmolecular-weight counter-ions upon complex formation. Thus, the structure and properties of IPEC depends on the characteristics of the polymers (charge density and molecular weight) and presence of other functional groups (hydrophobic moieties) and are affected by preparation parameters (concentration of polymers) and physicochemical properties of the solution $(\mathrm{pH}$, ionic strength, and temperature) (Fukuda, Kikuchi, 1979; Petrov, Antipov, Sukhorukov, 2003; Pergushov, Buchhammer, Lunkwitz, 1999; Kayitmazer, 2016). Given that IPECs do not always correspond to equilibrium structures because of the polymeric nature of the components, their properties are also be affected by other experimental variables, such as stirring speed and blending order (Kabanov, 1994).

Non-stoichiometric and stoichiometric complexes can be formed depending on the molar ratio of cationic to anionic groups. In the first case, the resulting complex contains an excess of one of the polyelectrolytes, thereby conferring the formed particle with surface charge and, in consequence, colloidal stability. By contrast, in a stoichiometric complex, positive and negative charges 
are mutually neutralized, and most of the formed particles precipitate due to colloidal instability (Kramarenko, Khokhlov, Reineker, 2006). When the polyelectrolytes are a weak acid and a weak base, their ionization degree will depend on the $\mathrm{pH}$ of the medium, allowing for tailoring of the composition of the resulting complexes, as well as colloidal stability (Petrov, Antipov, Sukhorukov, 2003). For instance, the combination of poly(butyl methacrylateco-(2-dimethylaminoethyl) methacrylate-co-methyl methacrylate) (EUE) and poly(methacrylic acid-comethyl methacrylate) (EUL) exhibits a weak acid and basic character attributed to the presence of methacrylic acid and 2-dimethylaminoethyl methacrylate monomers, respectively. At a given $\mathrm{pH}$ value, both polymers are oppositely charged, thus facilitating the formation of IPEC with different compositions.

This work aims to prepare a stoichiometric interpolyelectrolyte complex (SIPEC) composed of EUE and EUL, determine its physicochemical properties, and study the viability of its use as a hydrophilic matrix for the controlled release of dexibuprofen. In this study, several properties of pharmacotechnical interest, such as moisture sorption, swelling behavior, and powder flowability, of the SIPEC were characterized.

Dexibuprofen, also known as (S)-(+)-ibuprofen, is the most active enantiomer of ibuprofen that shows distinct advantages relative to the racemic mixture. The effectiveness of dexibuprofen as an analgesic and antiinflammatory drug is hampered by its poor solubility in water, which results in low bioavailability. Despite numerous reports on the development of delivery systems for ibuprofen, the systems cannot be suitable for dexibuprofen due to differences between their physical properties, such as solubility and crystallinity (Leising et al., 1996; Zhang et al., 2011; Kamari, Ghiaci, 2016; Aukunuru, Chinnala, Guduri, 2009; Padula, Nicoli, Santi, 2011; Patel et al., 2013; Zhu, Sham, 2014). Dexibuprofen is a weak acid and is thus partially deprotonated at $\mathrm{pH}$ values close to the intestinal values. A SIPEC seems to be a promissory matrix to control dexibuprofen solubility due to the feasibility of establishing both hydrogen bonds and electrostatic interactions.

\section{EXPERIMENTAL SECTION}

\section{Material}

Dexibuprofen was kindly supplied by Tecnoquimicas Bogota D.C. (Lote C102-1203021M). Eudragit ${ }^{\circledR}$ EPO, composed of poly(butyl methacrylateco-(2-dimethylaminoethyl) methacrylate-co-methyl methacrylate) with a monomer molar ratio of 1:2:1 (EUE), and Eudragit ${ }^{\circledR}$ L100, composed of poly(methacrylic acidco-methyl methacrylate) with a monomer molar ratio of 1:1 (EUL), were provided by Almapal Bogota, Colombia. Glacial acetic acid $\left(\mathrm{CH}_{3} \mathrm{COOH}\right)$ from Merck, sodium hydroxide from Panreac Quimica S.A., and potassium monoacid phosphate from Mallinckrodt were used as received. All assays were carried out using deionized water (conductivity $<18 \mu \mathrm{S} \mathrm{cm}^{-1}$ ).

\section{Determination of specific amount of amine and carboxylic acid group in polymers}

The specific amount of amine and carboxylic groups $(\mathrm{mmol} / \mathrm{g})$ on EUE and EUL was determined by titration with $0.10 \mathrm{M}$ perchloric acid and $0.10 \mathrm{M}$ $\mathrm{NaOH}$, respectively, according to a previously described procedure (Medicines, 2012; Baena, Manzo, 2011).

\section{Determination of SIPEC Composition}

For determining the ratio of polymers at which the stoichiometric complex is obtained, IPECs with the composition shown in Table I were prepared based on a procedure published by Moustafine et al. (2005). The corresponding amounts of EUE and EUL were initially dissolved in $0.1 \mathrm{M} \mathrm{CH}_{3} \mathrm{COOH}$ and $0.1 \mathrm{M} \mathrm{NaOH}$, respectively. The $\mathrm{pH}$ of both solutions was adjusted to 6.0 by adding $0.1 \mathrm{M} \mathrm{NaOH}$ in the case of EUE and 0.1 $\mathrm{M} \mathrm{CH}_{3} \mathrm{COOH}$ for EUL. Afterward, the solution of EUE was added to the corresponding solution of EUL, and the mixture was stirred at $580 \mathrm{rpm}$ for $2 \mathrm{~h}$ at room temperature.

For recovering the solid complex, the suspensions were centrifuged at $6500 \mathrm{rpm}$ for $1 \mathrm{~h}$. The resulting solid was dried at $45{ }^{\circ} \mathrm{C}$ for $48 \mathrm{~h}$, rinsed with deionized water, and dried again at the same temperature for $24 \mathrm{~h}$. The largest aggregates were removed using a sieve mesh \#60.

TABLE I - Interpolyelectrolyte compositions

\begin{tabular}{lccc}
\hline Sample & $\begin{array}{c}\text { EUL weight } \\
(\mathbf{m g})\end{array}$ & $\begin{array}{c}\text { EUE weight } \\
(\mathbf{m g})\end{array}$ & $\begin{array}{c}\text { Mol ratio of } \\
\text { amine to acid }\end{array}$ \\
\hline IPEC25 & 50.0 & 22.2 & $0.25: 1$ \\
IPEC50 & 50.0 & 44.4 & $0.50: 1$ \\
IPEC75 & 50.0 & 66.7 & $0.75: 1$ \\
IPEC100 & 50.0 & 88.8 & $1: 1$ \\
IPEC125 & 50.0 & 111.0 & $1.25: 1$ \\
IPEC150 & 50.0 & 133.2 & $1.50: 1$ \\
IPEC200 & 50.0 & 177.6 & $2: 1$ \\
IPEC250 & 50.0 & 222.0 & $2.5: 1$ \\
\hline
\end{tabular}




\section{Standard procedure for the preparation of a SIPEC}

The best experimental conditions to prepare a SIPEC with composition as determined as previously described, were determined using Taguchi experimental design. The starting solution of the corresponding precursors were prepared as described above. According to the experimental design, the highest SIPEC yield and water retention were achieved when EUE solution was dropped to the EUL solution at the mixing temperature and stirring speed of $25^{\circ} \mathrm{C}$ and $580 \mathrm{rpm}$, respectively. The SIPEC was separated from the resulting solution after $2 \mathrm{~h}$ and processed as indicated.

\section{Characterizations}

\section{Zeta potential measurements}

The measurements were carried based on the methodology early reported by Ciani et al. (2004). In a typical protocol, the colloidal dispersion prepared was diluted to $100.0 \mathrm{~mL}$. The values were directly measured in a Zetasizer Nano Z (Malvern), which employs the Hemholtz-Smoluchowski method based on electrophoretic mobility, and each one of the reported values corresponds to the average of five measurements of three different samples.

\section{Infrared analysis}

Two milligrams of each sample was dispersed in $100 \mathrm{mg}$ of $\mathrm{KBr}$, which was thoroughly homogenized and pressed to obtain thin discs. The spectra were acquired by transmittance in a Thermo Scientific Nicolet iS10.

\section{Thermal analyses}

Thermogravimetric analysis (TGA) was performed in a Mettler Toledo TGA $1 \mathrm{STAR}^{\mathrm{e}}$ system. In a typical experiment, the thermogram was acquired through heating the sample from room temperature to $800^{\circ} \mathrm{C}$ at $10^{\circ} \mathrm{C} / \mathrm{min}$ under nitrogen flow (50 $\mathrm{mL} / \mathrm{min})$.

DSC analysis run was acquired via differential scanning calorimetry (DSC) in a Mettler Toledo DSC $1 \mathrm{STAR}^{\mathrm{e}}$ system. The samples were heated from room temperature to $100{ }^{\circ} \mathrm{C}$ at $30^{\circ} \mathrm{C} / \mathrm{min}$, and then cooled to $-20^{\circ} \mathrm{C}$. Finally, the thermograms were acquired from -20 ${ }^{\circ} \mathrm{C}$ to $200{ }^{\circ} \mathrm{C}$ heating at $10{ }^{\circ} \mathrm{C} / \mathrm{min}$.

\section{Pharmacotechnical characterizations}

\section{Powder size and morphology}

Powder size and distribution were measured using an optical microscope G380 (UNICO) equipped with a Moticam 2000 camera. The reported values correspond to 500 measurements obtained using the software Motic Images Plus 2.0. The morphology of SIPEC and the corresponding individual components were characterized by scanning electron microscopy (SEM). The images were acquired in a JEOL JSM-6490LV microscope at 20 $\mathrm{kV}$. Prior to the analysis, the samples were sputter coated with gold, and the images were collected at $15 \mathrm{kV}$ using secondary electrons.

\section{Bulk and Tap Densities}

These parameters were determined following the procedure described in USP 37 (2008). For determining bulk density, the amount of the powder necessary to fill up a $5.0 \mathrm{~mL}$ graduated cylinder was weighed, and the ratio mass/volume was directly calculated. For tap density, the cylinder containing a given amount of powder was tapped 1000 times using a Powder Tapped Density Tester (Tap Density). The volume of the sample was read and used in the calculation.

\section{Moisture sorption isotherms}

Equilibrium moisture isotherms of EUL, EUE, and SIPEC were determined in the range of $32 \%$ to $96 \%$ relative humidity (RH). RH was controlled using saturated salt solutions, and $32 \%, 66 \%, 76 \%$, and $96 \% \mathrm{RH}$ were achieved using saturated solutions of $\mathrm{MgCl}_{2}, \mathrm{CaCl}_{2}$, $\mathrm{NaCl}$, and $\mathrm{Na}_{2} \mathrm{SO}_{4}$, respectively. Prior to the analysis, the powder was dried at $45^{\circ} \mathrm{C}$ for $48 \mathrm{~h}$. Sorption experiments were conducted at $19.0^{\circ} \mathrm{C} \pm 0.5^{\circ} \mathrm{C}$, and three specimens were analyzed for each sample at seven different times, namely, $(1,3,6,9,24,48$, and $72 \mathrm{~h}$, to detect equilibrium conditions according to methodology reported by Callahan (Callahan et al., 1982).

\section{Water sorption capacity}

A $200 \mathrm{mg}$ portion of the corresponding material was pressed into small $13-\mathrm{mm}$ discs under 50 psi for $15 \mathrm{~s}$. The specific volumetric water sorption capacity, taken as the volume of water uptake by mass unit of sample, was measured at $\mathrm{pH}$ value of 6.8 using an Enslin equipment following the methodology previously reported by Nogami et al. (1969)

\section{Evaluation of in vitro release of dexibuprofen}

On the basis of the methodology proposed by 
Baena et al. (2011), $200 \mathrm{mg}$ of SPEC and an equivalent amount of dexibuprofen were mixed mechanically and pressed under 50 psi for $1 \mathrm{~min}$ to obtain solid tablets. Dexibuprofen release from tablets was evaluated in a dissolution apparatus II (Hanson Research, USA). The experiments were carried out at $37.0{ }^{\circ} \mathrm{C} \pm 0.5^{\circ} \mathrm{C}$, $100 \mathrm{rpm}$, and a total dissolution volume of $900 \mathrm{~mL}$ of phosphate buffer at $\mathrm{pH}$ 6.8. The release of dexibuprofen was determined for $8 \mathrm{~h}$ with sampling of $5.0 \mathrm{~mL}$ at 5,15 , $30,60,120,180,240,300,360,420$, and $480 \mathrm{~min}$. The dissolution volume was kept constant by replacing the withdrawn volume with fresh medium. The concentration of dexibuprofen in the release medium was determined by UV-vis spectrometry at $264 \mathrm{~nm}$ by using a Shimadzu UV Spectrophotometer UV-1800 with a previously validated analytical methodology.

\section{RESULTS AND DISCUSSION}

\section{SIPEC Preparation}

In this work, EUE and EUL were used as cationic and anionic polymers, respectively. The corresponding specific amount of amino and carboxylic acid groups was determined by titration given at 5.6 and $3.23 \mathrm{mmol} / \mathrm{g}$, respectively. EUL exhibits a weak acid characteristic due to the methacrylic acid units $\left(\mathrm{p} K_{\mathrm{a}} \approx 6.0\right)$, whereas EUE presents a weak basic character due to 2-(dimethylamino) ethyl methacrylate $\left(\mathrm{p} K_{\mathrm{a}} \approx 7.5\right)$. Therefore, charge density is dependent on the $\mathrm{pH}$ of media. In this study, the $\mathrm{pH}$ was fixed at 6.0 to guarantee their solubility and the charged state of the polymers. As shown in Schemes 1A and 1B, EUE and EUL are polymeric substances with molecular weight around $50 \mathrm{kDa}$. In addition to bearing hydrophilic groups, the polymers also present hydrophobic segments whose interaction contributes to both stabilizing the complex and allowing the absorption of hydrophobic molecules.

For determining the molar ratio of EUE/EUL necessary to obtain a stoichiometric complex, the compositions listed in Table I were analyzed. The resulting colloidal dispersions were characterized by zeta-potential measurements with the corresponding values shown in Figure 1 as a function of the ratio of cationic to anionic groups. When the molar ratio of EUE to EUL were below 0.75 , the resulting coacervates form negatively charged colloidal particles, indicating an excess of carboxylic anions. However, at molar ratios exceeding 0.75 , the resulting colloidal particles exhibit a positive charge owing to the excess of $-\mathrm{NH}^{+}$groups. When the molar ratio of EUE to EUL is about 0.75 , the zeta potential approximates $0 \mathrm{mV}$, indicating that amine and carboxylate groups are nearly stoichiometrically balanced. At this composition, macrophase separation was also observed, allowing the complex to be removed from aqueous solution by filtration.

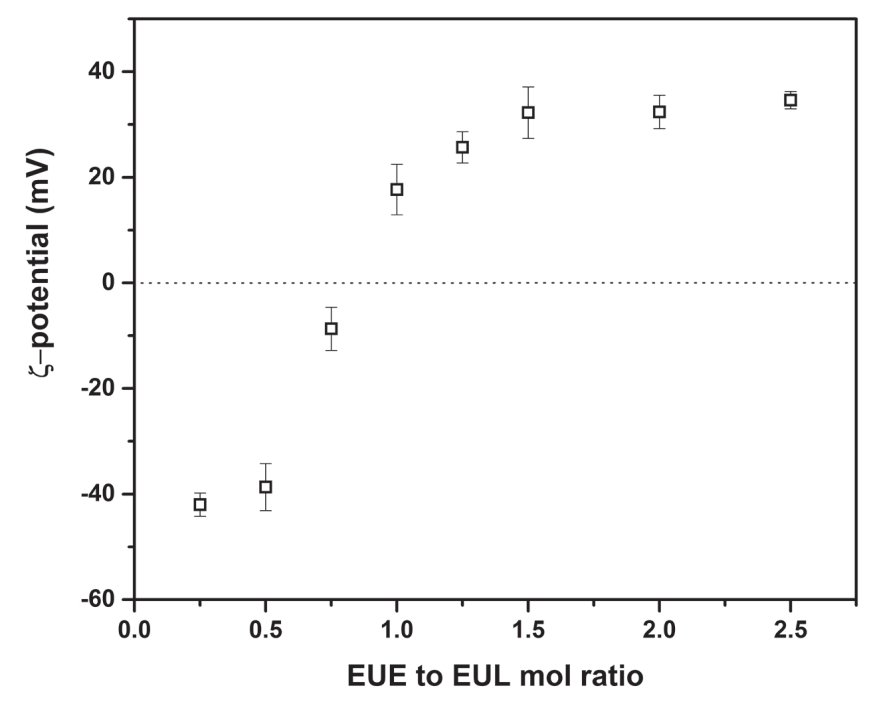

FIGURE 1 - Variation of $\xi$-potential as a function of IPEC composition.

A complex obtained with a molar ratio EUE to EUL of 0.75 and utilizing the optimum conditions was used for the subsequent characterization. Initially, this SIPEC was analyzed by Fourier transform infrared spectroscopy,
A

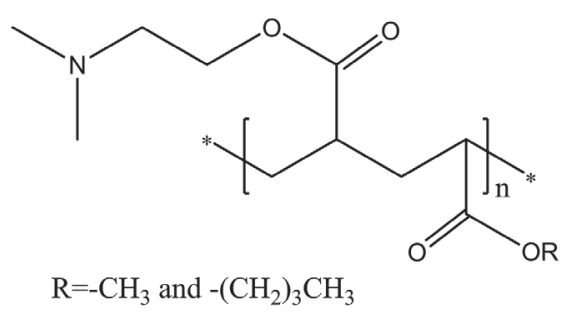

B

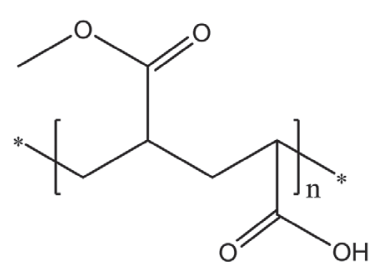

C<smiles>CC(=O)[C@H](C)c1ccc(CC(C)C)cc1</smiles>

SCHEME 1 - Chemical structure of A. EUE, B. EUL, and C. Dexibuprofen. 
and the corresponding spectrum was compared with the individual components and a physical blend of the components with identical composition (Figure 2A). While the physical blend shows the characteristic signals of both polymers (Moustafine, Kemenova, Van den Mooter, 2005; Moustafine, Zaharov, Kemenova, 2006), the SIPEC spectrum reveals several differences. A shoulder around $1557 \mathrm{~cm}^{-1}$, which was absent in the spectra of the individual components or in the blend, is related to the interaction of carboxylate ions with positively charged amino groups.

Not all amine groups on EUE are ionized and interacting electrostatically with carboxylate groups owing to their weak basic characteristic (Moustafine, Zaharov, Kemenova, 2006; Diaz, Perez, 2015) and their trapping into hydrophobic polymer domains that further decrease their basicity (Moustafine, Kemenova, Van den Mooter, 2005). Hence, a marked reduction of signals at $2776 \mathrm{~cm}^{-1}$ to $2884 \mathrm{~cm}^{-1}$ in comparison with those of the physical blend and EUE indicates that non-charged amine groups on SIPEC are almost extinguished. In addition, the appearance of a weak signal at $2781 \mathrm{~cm}^{-1}$ (Figure 2B), which does not correspond to vibrations of individual components, suggests that non-ionized amine and carboxylic acid groups interact through the formation of hydrogen bonds.

The DSC thermograms of EUE, EUL, SIPEC, and a physical blend with the same composition are shown in Figure 3. EUE and EUL present glass transitions at $46{ }^{\circ} \mathrm{C}$ and $71{ }^{\circ} \mathrm{C}$, respectively. The lowest $T_{\mathrm{g}}$ of EUE is due to the presence of butyl-methacrylate units, which confers flexibility to the polymer segments. Similarly, the high $T_{\mathrm{g}}$ of EUL reveals a decrease in segmental mobility due to the presence of stiff methyl methacrylate units and to intermolecular hydrogen bonding that involves pendant carboxylic acid groups (Van Krevelen, Te Nijenhuis, 2009). The SIPEC exhibits a single glass transition at $80^{\circ} \mathrm{C}$, indicating the miscibility of the polymers owing to the favorable ionic interactions (Pérez, Sierra, López, 2008). Presumably, $T_{\mathrm{g}}$ is larger than the corresponding value for individual components owing to electrostatic interactions responsible for the formation of the complex that reduces global mobility; however, other interactions, such as hydrogen bonds involving non-ionized groups and hydrophobic interactions, can also contribute to increased polymer entanglement. By contrast, the physical blend only shows $T_{\mathrm{g}}$ associated with EUE. The absence of transition associated to EUL may be due to its minor concentration in the blend and the glass transition for this individual polymer occurring in a broad temperature range.

EUL, EUE, their physical blend, and a SIPEC were analyzed by TGA, and the resulting plots are shown in Figure 4. EUL presents two degradation stages: the first at $300{ }^{\circ} \mathrm{C}$, which corresponds to a loss of $26 \mathrm{wt} . \%$ and is attributed to the loss of 2-dimethylaminoethyl moieties from DMAEMA units; the second degradation observed at $432{ }^{\circ} \mathrm{C}$ is attributed to the breakdown of the remaining structures to $\mathrm{CO}_{2}$ and other carbonization products (Roy et al., 2013). EUL profile presents a single degradation characteristic of methacrylate-based polymers (Manring, 1991). Both the physical blend and the SIPEC present

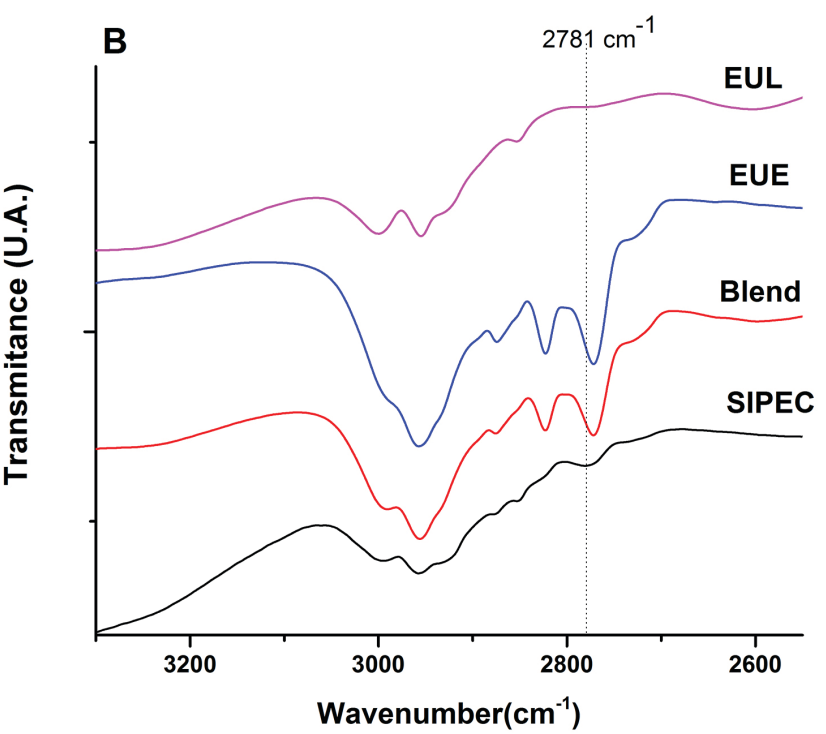

FIGURE 2 - A) Infrared spectra of the stoichiometric complex, a physical blend, and the individual components, and B) spectra zoom in the wavenumber range of $3300 \mathrm{~cm}^{-1}$ to $2650 \mathrm{~cm}^{-1}$. 


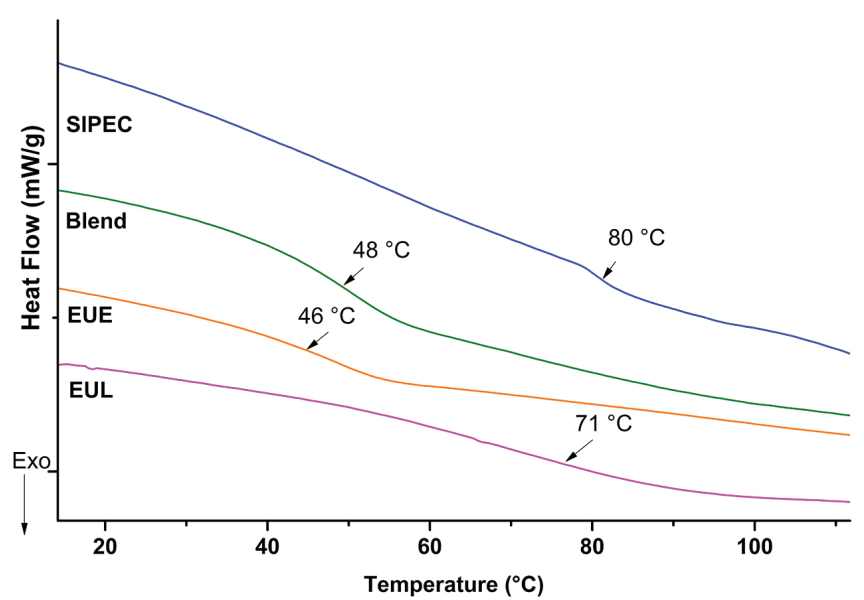

FIGURE 3 - DSC thermograms for individual polymers, SIPEC, and a physical blend with the same nominal composition.

two degradation temperature levels corresponding to the decomposition of both constituents. In both samples, the first loss, which is associated to the decomposition of DMAEMA units and corresponding to approximately 19 wt.\%, indicates that the complex and the physical blend present similar compositions; this finding is in good agreement with the high yield observed during preparation. The maximum degradation rate of the first loss on SIPEC occurs at lower temperature than the corresponding phenomena for EUE and the physical blend (Figure 4 inset). The interaction between amine and carboxylic groups decreases the breakdown energy and concomitantly increases molecular free volume and facilitates the diffusion of low-molecular-weight pyrolysis products.

\section{Pharmacotechnical properties}

Figure 5 presents SEM images of EUE, EUL, and their corresponding SIPEC. According to the images, the self-assembly of EUE forms amorphous particles with a broad size distribution, whereas EUL is in the

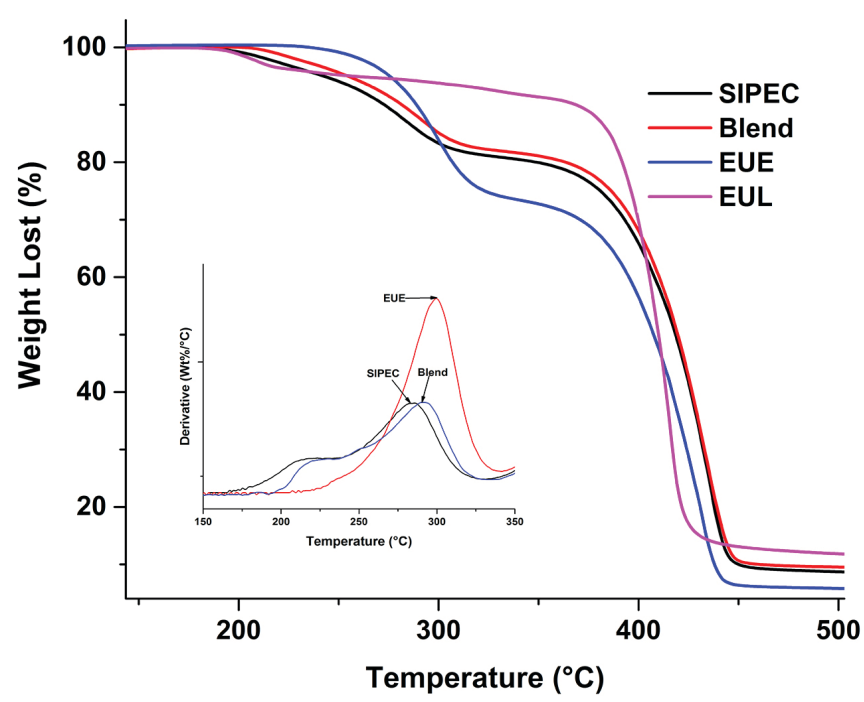

FIGURE 4 - TGA thermograms of the SIPEC, the physical blend, and the corresponding individual components. Inset shows weight derivative as a function of temperature for the first loss exhibited by samples.

form of rough spherical particles. The SIPEC complex is composed of large amorphous particles. Sizes of the particles measured employing optical microscopy are listed in Table II.

TABLE II - Particle size and distribution obtained from optical microscopic analysis

\begin{tabular}{lcc}
\hline & $\begin{array}{c}\text { Average } \\
\text { diameter }(\boldsymbol{\mu m})\end{array}$ & $\begin{array}{c}\text { Cumulative relative } \\
\text { frequency }(\mathbf{9 0 \%} \text { of Particles) }\end{array}$ \\
\hline EUE & 12 & $3-16 \mu \mathrm{m}$ \\
EUL & 23 & $8-24 \mu \mathrm{m}$ \\
SIPEC & 96 & $14-139 \mu \mathrm{m}$ \\
\hline
\end{tabular}

Table III lists the values of bulk and tap density of the individual precursor and the corresponding SIPEC. Density is closely related to particle morphology, size,


FIGURE 5 - SEM images: A) EUE, B) EUL, and C) SIPEC. 
A pH-responsive drug delivery matrix from an interpolyelectrolyte complex: preparation and pharmacotechnical properties

TABLE III - Density and flow properties

\begin{tabular}{lcccc}
\hline \multirow{2}{*}{ Sample } & \multicolumn{2}{c}{ Density $\left(\mathbf{k g} / \mathbf{m}^{\mathbf{3}}\right)$} & \multirow{2}{*}{ Carr's index } & \multirow{2}{*}{ Hausner Index } \\
\cline { 2 - 3 } & Bulk & Tap & 18.7 & 1.23 \\
SIPEC & $567.2 \pm 0.5$ & $698.0 \pm 4.6$ & 15.8 & 1.19 \\
EUL & $457.1 \pm 3.6$ & $543.1 \pm 7.8$ & 11.6 & 1.13 \\
EUE & $287.5 \pm 6.1$ & $325.4 \pm 17.0$ & \\
\hline
\end{tabular}

distribution, and other intrinsic properties of the materials (Aulton, 2002; Singh, 2006). In solid state, the particles aggregate depending on their shape and size, leaving spaces for low-density materials. As seen from data shown in Table III, the lowest density corresponds to EUE owing to its small particle size, narrow distribution, morphology, and the presence of pores as deduced from the rough surface of the particles seen by SEM. The largest density of SIPEC correlates well with its broadest particle size distribution (Table II) and amorphousness.

The Carr's index, which is estimated as $\left[\left(\rho_{\text {tap }}-\rho_{\text {bulk }}\right) /\right.$ $\left.\rho_{\text {tap }}\right] \times 100$, accounts for differences between apparent and tap densities. Carr's index characterizes the flow properties of the materials, with different intervals 5-10, 12-16, 18-21, and 23-28 indicating excellent, good, fair, and poor flow properties of the material, respectively (Carr, 1965). According to Carr's indexes given in Table IIII, both EUE and EUL and the SIPEC present good and fair flow properties, respectively (Kumar, de la Luz Reus-Medina, Yang, 2002; Bernal, Aragón, Baena, 2016).

By contrast, Hausner ratio of bulk to tap density and its relation to interparticle friction are shown on Table III. This ratio does not show significant differences in the evaluated samples given that all the cases approach 1.2, which indicates low interparticle friction and good flowability for SIPEC and for EUE and EUL. The lowest value obtained for EUE agrees with the presence of spherical particles.

The powder exposed to the atmosphere can adsorb moisture from the air, and the amount they adsorb is described by the equilibrium moisture sorption isotherm of the powder (Callahan et al., 1982; Dalton, Hancock, 1997). Moisture sorption of SIPEC and the individual polymers was assessed in the experimental range of $32 \%$ to $96 \%$ RH.. The resulting isotherms are shown in Figure 6A. The uptake of water by a solid is enhanced by establishing intermolecular interactions, such hydrogen bonds, ion-dipole, and dipole interactions, but not exclusively because the surface area of the particles and the presence of microporous and mesoporous are factors that influence water adsorption (Kontny, Grandolfi, Zografi, 1987; Rouquerol et al., 2013).
In Figure 6A, EUE presents the lowest moisture absorption because DMAEMA units with low protonation degree present a hydrophobic character, as observed from the insolubility of PDMAEMA in alkaline aqueous solutions (Diaz, Perez, 2015). This behavior agrees with the early reported application of EUE as a protective agent of water-sensitive substances (Bley, Siepmann, Bodmeier, 2009). By comparison, EUL presents larger values of moisture sorption owing to the presence of more polar carboxylic acid groups and also to the minor particle size.

The most notable hygroscopic behavior observed for SIPEC can be attributed to the presence of ionized groups, which interact strongly with polar water molecules. A SIPEC resulting from cooperative interactions of polymeric counterparts can presumably present larger free volume, allowing the solid to host an increased number of water molecules. According to the classification based on water uptake proposed by Callahan, the SIPEC reported in this work can be classified as a slightly hygroscopic excipient (Callahan et al., 1982) and act as a suitable excipient in pharmaceutical applications.

The swelling kinetic plots of SIPEC at three different $\mathrm{pH}$ values of $3,4.5$, and 6.8 are shown in Figure 6B. The plots reveal that the samples present an initial high swelling ratio during the first $2 \mathrm{~h}$ and is followed by a period of slow swelling. The swelling ratio evidently depend on the medium $\mathrm{pH}$, with the largest value observed at $\mathrm{pH} 3.0$, which also corresponds to the highest protonation degree of amine groups in the EUE. At pH 6.8 and 4.5, the SIPEC exhibits a similar swelling behavior, indicating that the swelling of SIPEC can be triggered by decreasing $\mathrm{pH}$, which possibly indicate a stimuli-sensitive release behavior.

The release profiles of dexibuprofen employing the SIPEC and a physical blend of EUL and EUE as matrixes at pH 6.8 are compared in Figure 7. As observed, the SIPEC provides a controlled release of the drug for $4 \mathrm{~h}$. By contrast, the release medium is saturated of dexibuprofen after 30 min when the physical blend is used.

The modified dissolution of dexibuprofen conferred by the SIPEC suggests that this substance interacts with the matrix through the formation of hydrogen bonds 

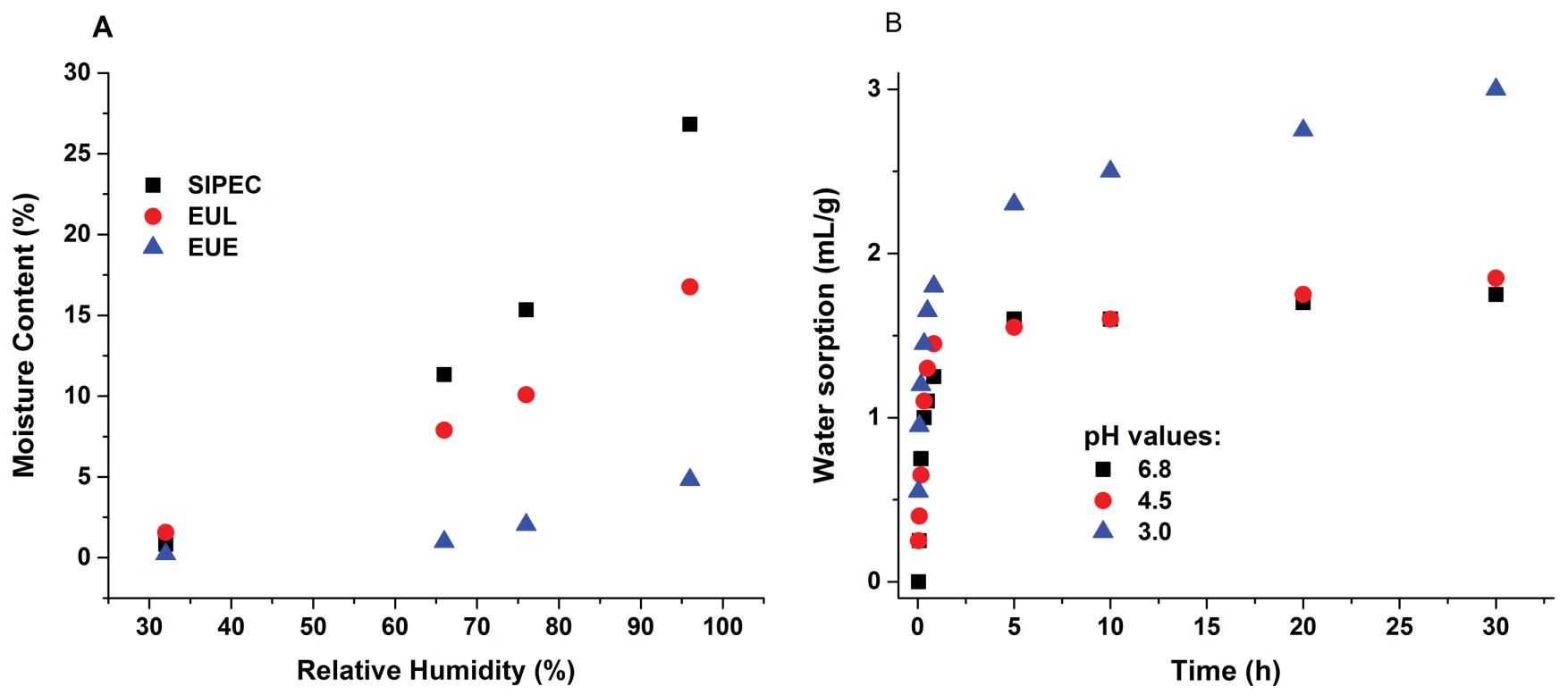

FIGURE 6 - A. Water sorption isotherms measured at $19^{\circ} \mathrm{C} \pm 1{ }^{\circ} \mathrm{C}$ of EUE, EUL, and the corresponding SIPEC. B. Swelling kinetics of SIPEC measured at different $\mathrm{pH}$ values.

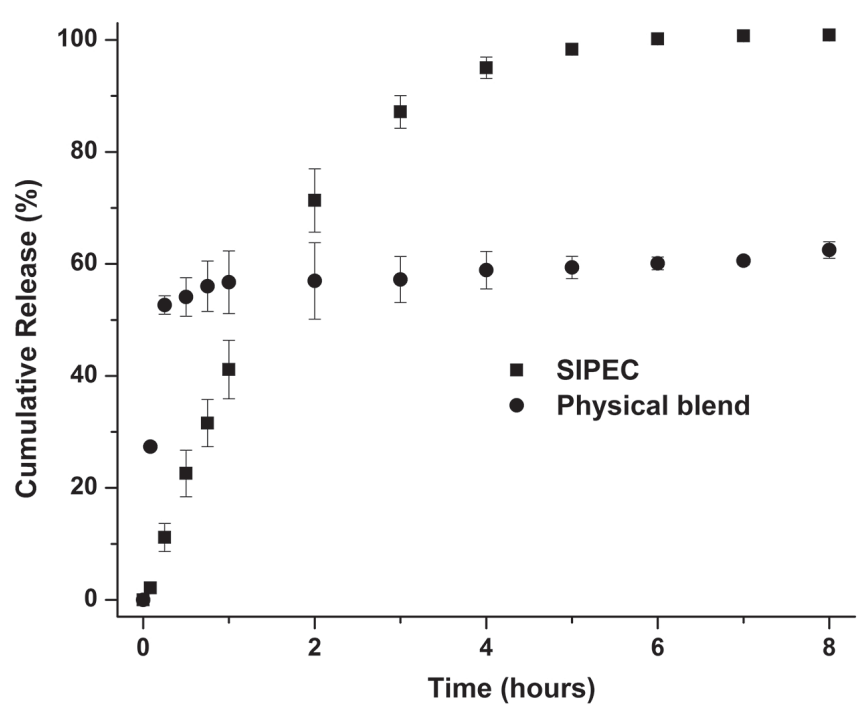

FIGURE 7 - Release profiles of dexibuprofen from a SIPEC and a physical blend of EUE and EUL as matrixes at $\mathrm{pH} 6.8$.

with non-ionized amine and carboxylic acid groups, electrostatic interactions, and Van der Waals forces with hydrophobic domains. The occurrence of specific interactions between the drug and the matrix determines the kinetics of drug release, and strong interactions are related to low release rates (Peña et al., 2016). In future research, improvement in release behavior exhibited by SIPEC matrixes will be addressed through the drug incorporation method. For instance, due to its acidic characteristic, dexibuprofen is partially deprotonated at $\mathrm{pH}$ 6.0, and its incorporation in colloidal state allows electrostatic interactions with positively charged amine groups in the EUE.

\section{CONCLUSIONS}

A stoichiometric interpolyelectrolyte complex (SIPEC) composed of poly(butyl methacylate-co(2-dimethylaminoethyl) methacrylate-co-methyl methacrylate)) (EUE) and poly(methacrylic acid-comethyl methacrylate) (EUL) was prepared at $\mathrm{pH}$ 6.0. Its composition assessed by $\zeta$-potential was 57 wt.\% in EUE and 43 wt. $\%$ in EUL. According to pharmacotechnical characterization, the SIPEC presents good flowability, slightly hygroscopic behavior, and $\mathrm{pH}$-dependent swelling. Furthermore, SIPEC can modify the solubility behavior of dexibuprofen. Thus, the SIPEC in this work exhibits potential for use in fabricating smart drug delivery systems.

\section{ACKNOWLEDGMENTS}

The authors thank COLCIENCIAS - Colombia by the support through the grant number 037-2016.

\section{REFERENCES}

Arora S, Gupta S, Narang RK, Budhiraja RD. Amoxicillin loaded chitosan-alginate polyelectrolyte complex nanoparticles as mucopenetrating delivery system for $H$. Pylori. Sci Pharm. 2011;79(3):673-694. 
Aukunuru J, Chinnala KM, Guduri V. Development of a novel transdermal ibuprofen ointment. Curr Trends Biotechnol Pharm. 2009;3(1):97-104.

Aulton ME. Pharmaceutics: The science of dosage form design. Edinburg: Churchill Livingstone; 2002.

Baena AY, Manzo RH. Preparation and physicochemical Characterization of some Polyelectrolyte-diclofenac complexes. Vitae. 2011;18(3):305-11.

Baena AY. Estudio fisicoquímico de la liberación del diclofenac a partir de complejos polielectrolito-fármaco. Bogotá: National University of Colombia; 2011.

Bawa P, Pillay V, Choonara YE, du Toit LC, Ndesendo VMK, Kumar P. A vomposite polyelectrolytic matrix for controlled oral drug delivery. AAPS PharmSciTech. 2011;12(1):227-38.

Bernal C-A, Aragón M, Baena Y. Dry powder formulation from fruits of Physalis peruviana L. standardized extract with hypoglycemic activity. Powder Technol. 2016;301:839-47.

Bley O, Siepmann J, Bodmeier R. Protection of moisturesensitive drugs with aqueous polymer coatings: Importance of coating and curing conditions. Int J Pharm. 2009;378(1-2):5965.

Čalija B, Cekić N, Savić S, Daniels R, Marković B, Milić J. pHsensitive microparticles for oral drug delivery based on alginate/ oligochitosan/Eudragit ${ }^{\circledR}$ L100-55 "sandwich" polyelectrolyte complex. Colloids Surf B Biointerfaces. 2013;110:395-402.

Callahan J, Cleary G, Elefant M, Kaplan G, Kensler T, Nash R. Equilibrium moisture content of pharmaceutical excipients. Drug Develop Ind Pharm. 1982;8(3):355-69.

Carr RL. Evaluating flow properties of solids. Chem Eng. 1965;72:163-8.

Ciani L, Ristori S, Salvati A, Calamai L, Martini G. DOTAP/ DOPE and DC-Chol/DOPE lipoplexes for gene delivery: zeta potential measurements and electron spin resonance spectra. Biochim Biophys Acta (BBA) Biomembranes. 2004;1664(1):70-9.

Dalton CR, Hancock BC. Processing and storage effects on water vapor sorption by some model pharmaceutical solid dosage formulations. Int J Pharm. 1997;156(2):143-51.
Devi N, Maji TK. Preparation and evaluation of gelatin/sodium carboxymethyl cellulose polyelectrolyte complex microparticles for controlled delivery of isoniazid. AAPS PharmSciTech. 2009;10(4):1412-9.

Diaz IL, Perez LD. Synthesis and micellization properties of triblock copolymers PDMAEMA-b-PCL-b-PDMAEMA and their applications in the fabrication of amphotericin B-loaded nanocontainers. Colloid Polym Sci. 2015;293(3):913-23.

Fukuda H, Kikuchi Y. Polyelectrolyte complexes of sodium carboxymethylcellulose with chitosan. Die Makromol Chem. 1979;180(6):1631-3.

Kabanov V. Physicochemical basis and the prospects of using soluble interpolyelectrolyte complex (review). Polym Sci. 1994;36:143-56.

Kamari Y, Ghiaci M. Preparation and characterization of ibuprofen/modified chitosan/TiO 2 hybrid composite as a controlled drug-delivery system. Microp Mesop Mat. 2016;234:361-9.

Kayitmazer AB. Thermodynamics of complex coacervation. Adv Colloid Interface Sci. 2016;239:169-177.

Kontny MJ, Grandolfi GP, Zografi G. Water vapor sorption of water-soluble substances: studies of crystalline solids below their critical relative humidities. Pharm Res. 1987;4(2):104-12.

Kramarenko EY, Khokhlov A, Reineker P. Stoichiometric polyelectrolyte complexes of ionic block copolymers and oppositely charged polyions. J Chem Phys. 2006;125(19):194902.

Kumar V, de la Luz Reus-Medina M, Yang D. Preparation, characterization, and tabletting properties of a new cellulosebased pharmaceutical aid. Int J Pharm. 2002;235(1-2):129-40.

Lankalapalli S, Kolapalli VM. Polyelectrolyte complexes: A review of their applicability in drug delivery technology. Indian J Pharm Sci. 2009;71(5):481-487.

Leising G, Resel R, Stelzer F, Tasch S, Lanziner A, Hantich G. Physical aspects of dexibuprofen and racemic ibuprofen. J Clin Pharmacol. 1996;36(12 Suppl):3S-6S.

Manring LE. Thermal degradation of poly(methyl methacrylate). 4. Random side-group scission. Macromolecules. 1991;24(11):3304-9. 
Medicines DftQo, Europe HotCo. European Pharmacopoeia. Strasbourg, France: Council of Europe; 2012. p. 1254.

Moustafine R, Kabanova T, Kemenova V, Van den Mooter G. Characteristics of interpolyelectrolyte complexes of Eudragit E100 with Eudragit L100. J Control Release. 2005;103(1):1918 .

Moustafine RI, Kemenova VA, Van den Mooter G. Characteristics of interpolyelectrolyte complexes of Eudragit E 100 with sodium alginate. Int J Pharm. 2005;294(1-2):113-20.

Moustafine RI, Zaharov IM, Kemenova VA. Physicochemical characterization and drug release properties of Eudragit ${ }^{\circledR} \mathrm{E}$ PO/Eudragit ${ }^{\circledR}$ L 100-55 interpolyelectrolyte complexes. Eur J Pharm Biopharm. 2006;63(1):26-36.

Nogami H, Nagai T, Fukuoka E, Sonobe T. Disintegration of the aspirin tablets containing potato starch and microcrystalline cellulose in various concentrations. Chem Pharm Bull. $1969 ; 17(7): 1450-5$.

Padula C, Nicoli S, Santi P. In vitro evaluation of bioadhesive films containing ibuprofen. Anti-Inflamm Anti-Allergy Agents Med Chem. 2011;10(3):240-5.

Patel A, Bell M, O'Connor C, Inchley A, Wibawa J, Lane ME. Delivery of ibuprofen to the skin. Int J Pharm. 2013;457(1):9-13.

Peña JA, Gutiérrez SJ, Villamil JC, Agudelo NA, Pérez LD. Polycaprolactone/polyvinylpyrrolidone/siloxane hybrid materials: Synthesis and in vitro delivery of diclofenac and biocompatibility with periodontal ligament fibroblasts. Mat Sci Eng C. 2016;58:60-9.

Pérez LD, Sierra L, López BL. Effect of the filler characteristics on the miscibility of styrene-butadiene rubber and nitrilebutadiene rubber blends. Polym Eng Sci. 2008;48(10):1986-93.

Pergushov D, Buchhammer H-M, Lunkwitz K. Effect of a low-molecular-weight salt on colloidal dispersions of interpolyelectrolyte complexes. Colloid Polym Sci. 1999;277(12):101-7.

Pergushov DV, Zezin AA, Zezin AB, Müller AH. Advanced functional structures based on interpolyelectrolyte complexes. In: Müller M. Polyelectrolyte complexes in the dispersed and solid state I. Berlin: Springer; 2013. p. 173-225.
Petrov AI, Antipov AA, Sukhorukov GB. Base-acid equilibria in polyelectrolyte systems: from weak polyelectrolytes to interpolyelectrolyte complexes and multilayered polyelectrolyte shells. Macromolecules. 2003;36(26):10079-86.

Ramasamy T, Tran TH, Cho HJ, Kim JH, Kim YI, Jeon JY, et al. Chitosan-based polyelectrolyte complexes as potential nanoparticulate carriers: physicochemical and biological characterization. Pharm. Res. 2014;31(5):1302-14.

Rouquerol J, Rouquerol F, Llewellyn P, Maurin G, Sing KS. Adsorption by powders and porous solids: principles, methodology and applications. Amsterdan: Academic Press; 2013.

Roy SG, Bauri K, Pal S, Goswami A, Madras G, De P. Synthesis, characterization and thermal degradation of dual temperature- and $\mathrm{pH}$-sensitive RAFT-made copolymers of N,N(dimethylamino)ethyl methacrylate and methyl methacrylate. Polym Int. 2013;62(3):463-73.

Singh Y. Martin's physical pharmacy and pharmaceutical sciences. New Jersey: Department of Pharmaceutics Ernest Mario School of Pharmacy Rutgers, The State University of New Jersey; 2006.

United States Pharmacopeia. USP. Pharmaceutical dosage forms-Powders. In: Pharmacopeia US, editor. USP 37, NF-32; 2008.

Van Krevelen DW, Te Nijenhuis K. Properties of polymers: their correlation with chemical structure; their numerical estimation and prediction from additive group contributions. Amsterdan: Elsevier; 2009.

Zhang J, Wang L, Wang D, Gong J, Li W, Wang J. Solubility of dexibuprofen in different solvents from (263.15 to 293.15) K. J Chem Eng Data. 2011;56(3):671-3.

Zhu YJ, Sham TK. The potential of calcium silicate hydrate as a carrier of ibuprofen. Expert Opinion Drug Deliv. 2014;11(9):1337-42.

Received for publication on 04th April 2017 Accepted for publication on 17th July 2017 